Revised Version

March 15, 2004

Comments Solicited

\title{
Associate Professor Turnover at America's Public and Private Institutions of Higher Education
}

\section{By}

\section{Matthew P. Nagowski *}

\begin{abstract}
This paper uses data from the American Association of University Professors annual salary survey to compute continuation rates for associate professors at American colleges and universities during the 1996-97 to 2001-2002 period. Findings demonstrate that average continuation rates are higher for private academic institutions than for public academic institutions in bachelors-level, masters-level and doctoral-level institutions. Multivariate analyses indicate that the average level of faculty compensation at an institution is an important predictor of the continuation rate. All other things held equal, institutions with higher average faculty compensation have higher continuation rates. However, the magnitude of this relationship is not sufficiently large enough to warrant change in compensation policies at academic institutions, particularly between public and private institutions. The benefits associated with raising average faculty compensation to increase the tenured faculty's continuation rates at public universities are unlikely to match or exceed the costs of doing so.
\end{abstract}

\footnotetext{
* Nagowski is a junior at Cornell University and a research assistant at the Cornell Higher Education Research Institute (CHERI). He would like to thank Ronald Ehrenberg for his continuous support and encouragement during the research process, as well as Michael Rizzo and anonymous referees for helpful comments on previous versions of this paper. He is grateful to the Andrew W. Mellon Foundation and Atlantic Philanthropies (USA) Inc. for supporting this research through their support of CHERI and to the American Association of University Professors (AAUP) for granting CHERI access to their data. However, all opinions that are expressed in the paper are strictly his own, as are any errors.

Access to the data used in this paper may be limited because of the confidential nature of the submissions of some institutions to the AAUP.

Nagowski may be contacted at the Cornell Higher Education Research Institute, 256 Ives Hall, Ithaca, NY 14853. Tel: (607) 2554424 \& Fax: (607) 255-4496. His email address is nagowski@cornell.
} 


\section{Introduction}

Voluntary departures of tenured faculty at an academic institution prior to the normal retirement age provide both benefits and costs to institutions of higher education. Benefits of faculty turnover to an institution include the ability to hire younger faculty members with previously committed salary funds, the ability to reallocate resources across program areas, and to provide the opportunity for the institution to diversify its faculty among gender, race and ethnic lines. Associated costs of faculty turnover include disruptions and the loss of continuity in teaching and research programs, in graduate and undergraduate advising, and in departmental and institutional governance and cohesiveness. Moreover, the size of the start-up package per faculty member that research universities incur when they must replace departing senior scientists and engineers by new assistant professors is now often in the $\$ 300,000$ to $\$ 500,000$ range (Ehrenberg, Rizzo and Jakubson 2002). Additional costs of faculty turnover are not as quantifiable, possibly affecting an institution along the more qualitative terms of faculty morale or academic reputation.

Therefore, each academic institution should weigh the benefits and costs of turnover, relative to its own needs and institutional situation, to establish an optimum target level of voluntary turnover among its tenured faculty. To do so, an institution needs to understand the determinants of its tenured faculty turnover rate, as well as to have information on trends in turnover rates nationwide. Although no exhaustive data on national turnover rates of faculty is published, each year the American Association of University Professors (AAUP), as part of its annual salary survey, collects information at the institutional level on the number of continuing faculty members in each rank. Continuing faculty members are defined as full-time faculty members employed in the rank in the previous year that also are employed full-time at the 
institution in the current year, regardless of their academic rank in the current year. For example, a faculty member who is an associate professor one year and promoted to full professor status in the next year will be counted as a continuing associate professor in the second year in the AAUP salary survey.

Subject to some qualifications, information on the number of continuing faculty members at an institution in a rank one year, coupled with information on the number of faculty members at the institution in the rank in the previous year, allows for the computation of a continuation rate for faculty members in the rank at the institution. This is done by dividing the number of continuing faculty members in the rank in one year by the total number of faculty members in the rank in the previous year. ${ }^{1}$ For example, the associate professor continuation rate is given by equation (1):

(1) $C R_{I t}=\frac{\text { cont_assofac }}{\text { total_assofac }}$,

where $C R_{I t}$ is the continuation rate for associate professors at institution $I$ in year $t$, cont_assofac It is the number of continuing full-time associate professors at the institution in year $t$, and total_assocfac $c_{I t-1}$ is the total number of full-time associate professors at the institution in year $t-$ 1.

It follows that the institution's turnover rate of full-time associate professors $T_{I t}$ is simply one minus its continuation rate or,

(2) $T_{I t}=1-C R_{I t}$.

The continuation rate for assistant professors cannot be used as a measure of voluntary turnover for assistant professors because some assistant professors leaving an institution do so

\footnotetext{
${ }^{1}$ The qualifications relate to the treatment of faculty members who are serving as administrators or who are on leave in either the previous or current year. The presence of such individuals introduces possible measurement error into the calculation.
} 
involuntarily when they are turned down for tenure. Similarly the continuation rate for fullprofessors is contaminated by faculty departures due to retirement, disability or death. Therefore, it is fair to assert that the continuation rate for associate professors, most of whom are tenured faculty members, comes closest to approximating a measure of voluntary turnover that is likely to be influenced by characteristics that are most under the control of the institution, including its average faculty compensation level. For these reasons, associate professor turnover at institutions of higher education is the sole component of investigation in this study, as the experience of associate professor turnover will be the most relevant reference for higher education administrators attempting to manage the amount of voluntary faculty turnover at their institution. Two earlier papers that have explored faculty continuation rates have been Ehrenberg, Kasper, and Rees (1991) and Rees (1994). The former study found that faculty continuation rates were remarkably stable at academic institutions across faculty levels during the 1970s and 1980s, while also ascertaining in a cross-sectional analysis that a high amount of association exists between compensation levels and continuation rates among associate professors at an institution. Meanwhile, Rees (1994) explored continuation rates during this time period further by utilizing panel data to discern the impact that unionization has on faculty retention rates. His findings demonstrate that both increased unionization and higher compensation levels decrease the amount of voluntary faculty turnover present at an academic institution. This paper is intended as an update and a synthesis of these two previous papers, with an explicit applied interest in the differences in faculty continuation rates that exist between public and private institutions of higher education. As the documented "resource gap" between public and private institutions continues to grow, what consequences are there for the voluntary turnover of professors? 
This paper utilizes the individual institutional level data upon which the published AAUP salary survey results are based to compute continuation rates for associate professors during the 1996-97 to 2001-2002 period. ${ }^{2}$ The next section presents aggregate continuation rates, by both institutional category and public/private form of control during the period studied. Section III uses the AAUP institutional level data and data from other sources to estimate continuation rate equations. A key concern of this paper, as well as to college and university administrators, is the level of average faculty compensation at an institution and its effect on professorial turnover. Moreover, the effect that certain labor market institutions and demographics have on faculty turnover is explored, so that an understanding of an individual institution's turnover levels within the broader context of the academic labor market may be obtained. Section IV details these concerns with respect to public and private institutional differences in continuation rates. The last section of this paper presents a brief conclusion.

\section{Aggregate Faculty Continuation Rates, 1996-1997 to 2001-2002}

While the vast majority of academic institutions report salary level data by academic rank to the AAUP each year, the number reporting continuing faculty data is much smaller and varies across years. In addition, each year a number of institutions report a number for continuing faculty that is larger than the number of faculty they reported in total in the previous year; these observations had to be eliminated from the sample. Only institutions for which data to be used in the regression analysis could be obtained are included in this paper's data set.

\footnotetext{
${ }^{2}$ Both Ehrenberg, Kasper and Rees (1991) and Rees (1994) have previously used the AAUP study to analyze the continuation rates of associate professors during the 1970s and 1980s. The AAUP also provided the author with data on continuing faculty between 1989-1990 and 1995-1996, but these data have been omitted in this study due to the absence of variables reporting the percentage of tenured professors and the percentage of female professors.
} 
Appendix Table 1 indicates the total number of institution/year observations in the original AAUP data set, broken down by type of institutional control (public or private) and highest degree granted (PhD, Masters, Bachelors, Two-year). The table also shows the number of observations available in what is called this paper's variable sample - a sample that includes all possible yearly institutional observations that contain complete data. Finally, it indicates the number of observations available in the constant sample - a sample in which institutions must have reported good continuation rate data (as well as other data for the multivariate analysis) each year to be included.

Computed continuation rates are very similar each year, by institutional category and form of control, between the two samples. Results are only reported for the constant sample in this section to minimize concerns that the means may have been driven by the changing institutional characteristics of the variable sample. ${ }^{3}$

One of the primary findings of Ehrenberg, Kasper, and Rees (1991) was the relative stability of the aggregate continuation rates over the course of the $1971-1972$ to $1988-1989$ period. For all institutions and years in that study, the weighted (by faculty size) mean continuation rate across institutions was 0.917 , with a maximum of 0.93 in 1986-1987 and a minimum of 0.90 in 1971-1972. This paper's findings indicate that the aggregate continuation rate for associate professors continued to be remarkable stable during the 1996-97 to 2001-2002 period. For the constant sample of institutions, the mean weighted continuation rate during the six years was again .917 . The weighted mean continuation rate peaked at .927 in 1996-97 and reached a low of .909 in 2000-2001.

However, experiences differed in the continuation rates between private and public academic institutions. Figure 1 plots the weighted (by number of faculty) average associate

\footnotetext{
${ }^{3}$ Results for the variable sample are available from the author.
} 
professor continuation rates for each of the 6 years, broken down by public and private form of control, which depicts a sustained difference between the continuation rate that exists at public institutions as compared to private institutions. This difference persists when continuation rates are broken down by the highest degree offered by an institution, too. Table 1 offers the weighted mean continuation rates at different classifications of four-year institutions, again presented by form of control. ${ }^{4}$ The average continuation rates for private doctoral degree granting institutions, masters degree granting institutions, and bachelors degree granting institutions were greater than that for their public counterparts in each year of this study. While one cannot infer causation from these simple comparisons, it is well known that average salaries of faculty at public higher education institutions were substantially lower than the average salary of faculty at private higher institutions during the period. ${ }^{5}$ Hence these findings do suggest that one possible cost of public higher education institution's low relative faculty salaries may be the higher levels of associate professor turnover that they experience.

\section{The Determinants of Associate Professor Continuation Rate}

Data from both the constant sample and the variable sample are used to estimate the determinants of associate professor continuation rates. Data for all institution/year observations between 1996-97 and 2001-2002 for which good continuation rate data are available are used in each case. For each sample, both a weighted linear probability function models, which offers coefficients that are easy to interpret, and a logit model, which has the advantage of constraining the predicted probabilities that are estimated to vary between 0 and 1 and of having normally distributed error terms, are used. Neither Ehrenberg, Kasper, and Rees (1991) nor Rees (1994)

\footnotetext{
${ }_{5}^{4}$ No private two-year institutions were included in the constant sample, hence their exclusion in these comparisons.

${ }^{5}$ F. King Alexander (2001) and Ronald Ehrenberg (2003)
} 
utilized a logit model, which means that their results could have very well predicted a theoretically impossible continuation rate for a particular institutional observation.

In the linear probability function model, the continuation rate for institution I in year $t$, $C R_{I t}$, is specified to be linearly related to a constant, $\alpha$, a vector of variables, $\mathrm{X}_{I}$, that represent institutional characteristics that do not vary over time, a vector of variables that represent institutional characteristics that do change over time, $Y_{I t}$, and an error term, $\varepsilon_{I I}{ }^{6}$

$$
C R_{I t}=\alpha+X_{I} \beta+Y_{I t} \delta+\varepsilon_{I t}
$$

Meanwhile, the logit model specifies the dependent variable to be the logarithm of the odds ratio of the continuation rate - or the ratio of the continuation rate for an institution in a year to one minus the continuation rate for the institution in that year $\left(L C R_{I t}\right)^{7}$

(4) $L C R_{I t}=\ln \left(\frac{C R_{I t}}{1-C R_{I t}}\right)$

In each of these models, $X_{I}$, the vector of variables that do not change with time, is specified to include a dichotomous variable for whether faculty at the institution are represented by a union $(U N I O N)$. Although Rees (1994) found the number of years of union organization at an institution to be a statistically significant determinant of faculty turnover, he did not find the mere presence of a faculty union to affect an institution's associate professor continuation rate. This paper will assess whether or not the affect of unionization has changed among public institutions. ${ }^{8}$ Also incorporated in this vector of variables are dummy variables indicating the

\footnotetext{
${ }^{6}$ Dichotomous variables, $T E N_{-} R E P$ and $S A T \_R E P$ are also included in the model to control for nonreporting of any of the explanatory variables.

${ }^{7}$ When calculating $L C R_{I t}$, observed values of 1.00 for $C R_{I t}$ are replaced with 0.9999 , as to not result in an indeterminate odds ratio.

${ }^{8}$ Because of the Supreme Court decision in the Yeshiva case, collective bargaining for faculty in the United States is primarily a public sector phenomenon. Hence the $U N I O N$ variable will be zero for all private university observations and its coefficient will capture the impact of faculty collective bargaining coverage on faculty continuation rates in public universities. NLRB V. Yeshiva University, 944 U.S. 672(1980)
} 
form of control for an institution (PRIV), associated with a church $(C H U R C H)$, and the highest degree granted by the institution ( $P H D, M A, B A)$ which are all included to accommodate for the fact that the academic labor market is largely segregated based on type of institution, and that faculty employed in different types of academic settings might have very different employment interests. For instance, associate professors working at institutions that only award bachelor's degrees might not be inclined to work at a research university that grants PhDs. The $X_{I}$ vector also includes a measure of the academic caliber of the institution's undergraduate students, measured by the mean SAT score of the institution's entering freshman class in 1998-1999 (SAT). ${ }^{9}$ In theory, faculty who teach brighter students might have a higher propensity to change institutions as they are more likely to be well-respected and highly sought after by other institutions. Such a theory is supported by the findings of Ehrenberg, Kasper and Rees (1991), which showed that all other things equal, schools with more competitive admissions tend to have a lower faculty retention rate.

The vector $Y_{I t}$, which encompasses those explanatory variables that vary for an institution over time, is specified to include the average associate professor compensation (wages and benefits) in thousands of dollars in year $t(C O M P)$, the percentage of associate professors at the institution that were tenured in that year $(T E N)$, and the percentage of associate professors that were female during that academic year (FEM). These three variables come from the AAUP survey. Theoretically, higher average salary levels and higher incidents of tenure among associate faculty should give faculty a stronger incentive to remain at their home institution.

\footnotetext{
${ }^{9}$ Data regarding an institution's public or private nature, religious affiliation, and highest degree offered were all included in the AAUP data set. Faculty collective bargaining data come from Hurd and Forester (1997) and are for colleges and universities with unionized faculty in the 1996-1997 school year, the last year such a study was published. The author calculated mean SAT data by averaging the $25^{\text {th }}$ and $75^{\text {th }}$ SAT percentile scores for incoming freshman in 1998-1999, taken from the CEEB's Annual Survey of Colleges Standard Research Compilation, 19981999. When only ACT scores were reported, the author converted such scores into SAT scores using the conversion chart found at http://www.ccsd.edu/south/Guidance/satconversion.htm.
} 
Meanwhile, the percentage of female faculty is included as a variable to control for possible gender influences upon a turnover rate. Females may have a higher propensity to stay at a home institution due to family obligations, or conversely, family obligations might cause a female faculty member to leave the labor market.

Table 2 presents the means of all of these variables, in both the constant and variable dataset, based on form of institutional control, for all observations and years in this study. Over time, the yearly weighted averages of the time sensitive variables either remained remarkably constant $(T E N)$ or demonstrated a steady, unwavering increase (COMP, FEM) within their sample and form of control, with the absolute differences between the public and private aggregates remaining steady as well. As the $U N I O N$ and $S A T$ variables were only obtained from one academic year, their values do not change over time.

Finally also included in the models are 6-year dichotomous variables, Y96, Y97, Y98, $Y 99, Y 00$, and $Y 01$, to control for omitted year specific factors that might influence associate professor continuation rates - such as the cost of living or the general trends of the academic labor market in a given year.

Table 3 exhibits the estimated coefficients obtained for both the variable and constant sample data sets, with both the linear probably model and the logit model results present. Findings from these models are very similar across both data sets (constant and variable sample) and both model specifications (linear and logit). ${ }^{10}$

\footnotetext{
${ }^{10}$ A fixed effects model similar to the one successfully utilized in Rees (1994) was also employed in an attempt to isolate intra-institutional determinants of associate professor continuation rates. However, the results of such a model were highly inconclusive, reporting coefficients that were positive in some models and negative on others, but rarely statistically significant. These results possibly suggest that not enough observations and years are present in this study for the successful employment of a fixed effects model, or alternatively that faculty turnover decisions are not based upon single year changes in average compensation levels. Individual-level data might prove to be more conclusive.
} 
Perhaps the most important finding from these results is that the average associate professor compensation level at an academic institution is positively related to its associate professors' continuation rates, other factors held constant; a result also found by Ehrenberg, Kasper, and Rees (1991). This finding is present in all but the logit model performed on the variable sample, where the coefficient is not statistically significant. In particular, the linear probability function models imply that a $\$ 10,000$ dollar increase in the average associate professor's compensation at an institution is associated with a $0.4(0.7)$ percentage point increase in the institution's associate professor retention rate in the variable (constant) sample data.

Moreover, all other factors held constant, including faculty compensation, continuation rates are about 1.5 to 2.5 percentage points higher at private academic institutions than they are at public institutions. This implies that, holding compensation levels constsant, some characteristics associated with different institutional forms of control, be they institutional size, the extent of bureaucracy, or stronger allegiances to private institutions or, differences in the nature and scope of employment, make faculty more attached to private academic institutions than they are to public academic institutions. Thus, some of the differences in continuation rates between public and private institutions displayed in Figures 1 and Table 1 are clearly due to factors other than the differences in average levels of compensation between the two types of institutions. The meanings of this finding will be explored further in Section IV of this paper.

Other determinants were also found to be associated with an academic institution's associate professor continuation rate. As some associate professors are nontenured and are subject to involuntary termination, it is not surprising to find that the higher the percentage of associate professors that have tenure on a campus, the lower the turnover rate is among the institution's associate professors. Moreover, evidence from the variable sample's linear 
probability model shows that an increase in the share of associate professors that are female at an institution is associated with a higher continuation rate, and thus a lower turnover rate for associate professors at the institution. This finding suggests that perhaps non-employment factors, such as family concerns, limit the ability of female associate professors to leave their positions; however, no statistically significant gender differences appear when the logit model or the smaller constant sample is used.

Results from the constant sample, and from the logit model of the variable sample results, suggest that all other factors held constant, including compensation levels, institutions with faculty unions have statistically significant higher continuation rates. Therefore, evident from these data, and echoing the findings of Rees (1994), having a faculty union is a non-pecuniary condition of employment that many faculty members value for more than just an increase in compensation. Faculty members may appreciate the added voice and mechanisms for governance that a union gives them within the operations of a public institution of higher education.

While the academic caliber of an institution's undergraduates is not found to have a relationship to an institution's associate professor continuation rate in all but one of the models, church affiliated institutions are oddly found to have lower levels of associate faculty retention in the logit model of both samples, but not in the linear probability model. No attribute of the datasets appears to explain these curious results.

The coefficients on the highest-degree level granted variables imply that all of the institutions that grant four-year degrees have lower continuation rates for full-time associate professors than do the two-year degree granting institutions (the omitted class). Among the PhD, $\mathrm{Ma}$, and Ba degree granting (four-year) institutions, the lowest continuation rates, and hence the highest turnover rates for associate professors, are seen to be at the $\mathrm{PhD}$ granting institutions for 
all but one of the models. Faculty at the PhD granting institutions are more likely to be more research oriented and to have more of a national market than their colleagues at more teaching oriented universities. In turn, they are likely to have higher voluntary turnover rates.

Finally, the coefficients of the year dichotomous variables (2001-2002 is the omitted year) reflect what is observed in the aggregate continuation rate data, namely that over the 6 year period associate professor continuation rates trended downward slightly by about 2.0 to 3.0 percentage points. In another words, voluntary turnover rates of associate professors increased slightly during the period in question.

\section{Remarks on Public and Private Institutional Differences}

The most important conclusion from this paper, which reiterates the findings of Ehrenberg, Kasper and Rees (1991) and Rees (1994), is that associate professor continuation rates are positively associated with the average level of compensation that associate professors receive. Holding other factors constant, including the public/private control of an institution, unionization of faculty, and the highest degree that the institution grants, a $\$ 10,000$ increase in associate professor compensation is associated with a 0.4 to 0.7 percentage point increase in its associate professor continuation rate and thus an equivalent decline in its associate professor turnover rate. Secondarily, this paper has documented a significant difference in the continuation rates that exists between associate professors of public and private institutions.

These estimates should be considered an upper bound of the improvement in associate professor continuation rates that an academic institution might expect to observe if it actually increased its faculty members' average compensation relative to its competitors' average 
compensation by $\$ 10,000$. This is due to the fact that this analysis omitted other variables that may vary across institutions systematically with average faculty compensation levels.

Thus, part of what these estimates suggest is that the effects of higher average compensation on continuation rates may actually reflect the effects of other conditions of employment, such as lower teaching loads or higher amounts of institutional prestige. To extend the example of lower teaching loads among research-oriented institutions, increasing average faculty compensation at an institution without also simultaneously reducing its faculty members' teaching loads would thus likely lead to a smaller increase in its faculty continuation rate than this paper's estimates suggest.

Along a similar line of reasoning, the large differences that exist between public and private continuation rates may be reflecting aspects of faculty employment in this study that are hidden, such as the diminished availability of research funds or higher teaching loads. It is with these types of understandings that the coefficients presented within this paper must truly be considered an upper limit on the effects of different institutional employment characteristics.

In 2000-2001, the difference between the average compensation of associate professors at private doctoral and public-independent doctoral institutions was in the range of $\$ 13,500$ (Bell 2001, Table 4). The estimates found in this paper suggest that if public doctoral universities were to increase their average associate professor compensation level by $\$ 10,000$ and substantially close this gap, they would at most increase their associate professors continuation rates by about 0.7 percentage points, which would still leave them with a lower average continuation rate than that of their private counterparts, as demonstrated in Table 1. In other words, for each 100 associate professors that an institution were to employ, it would cost more than an extra \$1 
million a year in faculty compensation to reduce its associate professor's turnover rate by one faculty member.

It is highly unlikely that these hypothetical actions would make sense for an institution to engage in for the purposes of increasing their faculty continuation rate. While lower average faculty salaries at public universities may influence the ability of public academic institutions to hire the very best faculty, they do not appear to substantially influence their existing faculty members' turnover rates. Thus, other institutional factors that are not explicitly accounted for in this study are clearly present in influencing the voluntary turnover of faculty at academic institutions.

These assertions are not, in any way, a suggestion that it would behoove institutions to limit their increases in faculty compensation. Increasing average compensation levels could provide an academic institutions with several rather beneficial results asides from diminished amounts of faculty turnover, including the facts that increased compensation can help to avert strikes (in those states where public employees can legally strike), attract better faculty, increase productivity incentives, and improve teaching quality and morale.

\section{Conclusion}

This study has served as both an update and as a fusion of previous literature on the subject of voluntary faculty turnover at American institutions of higher education. Using data provided by the American Association of University Professors, an understanding on the trends and determinants affecting the voluntary turnover of associate professors between the academic years of 1996-1997 through 2001-2002 has been obtained. In general, continuation rates, although declining in recent years, have remained relatively stable, and both the average level of 
compensation among faculty at an academic institutions and the presence of a faculty union, among other variables, remain key determinants to the level of faculty turnover at any particular institution.

Moreover, faculty turnover has continued to be remarkably differentiated between public and private institutions of higher education during the time period of this study, and the increasingly growing resource gap between public and private higher education institutions has most certainly helped to perpetuate this fact. But, as the results of this study suggest, it appears that even if the differences in average salaries between public and private institutions were ameliorated, non-pecuniary conditions of public school employment would continue to push down public-sector faculty turnover relative to their private-sector counterparts. What remains to be analyzed, however, are how individual faculty characteristics and experiences influence the phenomenon of faculty turnover.

\section{References}

Alexander, F. King, "The Silent Crisis: The Relative Fiscal Capacity of Public Universities to Compete for Faculty", Review of Higher Education. 24 (Winter 2001)

Annual Survey of Colleges Standard Research Compilation, 1998-1999

College Entrance Examination Board. New York, NY: The College Entrance Examination Board, 1998.

Bell, Linda, "Uncertain Times: The Annual Report on the Economic Status of the Profession 2000-2001”, Academe 87 (March/April 2001): 27-49. 
Ehrenberg, Ronald G. Tuition Rising: Why College Costs So Much. (Harvard University Press, 2000: Cambridge MA).

Ehrenberg, Ronald G., "Studying Ourselves: The Academic Labor Market”, Journal of Labor Economics: (April 2003):

Ehrenberg, Ronald G., Rizzo, Michael R. and George H. Jakubson, "Who Bears the Growing Cost of Science at Universities" (Cornell Higher Education Research Institute Working Paper 35, April 2003) Available: http://www.ilr.cornell.edu/cheri

Ehrenberg R., Kasper H., and Rees D. "Faculty Turnover at American Colleges and Universities: Analysis of AAUP Data," Economics of Education Review 10 (1991): 99-110. Freeman, Richard B. "The Exit Voice Tradeoff In the Labor Market: Unionism, Job Tenure, Quits, and Seperation." The Quarterly Journal of Economics. 94 (1980): 643 - 673.

Hamermesh, Daniel S. "Quite Good News-For Now," Academe (March-April 2002) Hurd, Richard and Amy Forester, Directory of Faculty Contracts and Bargaining Agents in Institutions of Higher Education. 23 (National Center for the Study of Collective Bargaining in Higher Education, 1997: Washington, DC)

Rees, Daniel I., "Does Unionization Increase Faculty Retention?" Industrial Relations. 33 (July 1994): 297-321.

Weiler, William C. "Why Do Faculty Member's Leave a University?” Research in Higher Education. 23 (1985) 270 - 278.

Zoghi, Cynthia. "Why Have Public University Professors Done So Badly?" Economics of Education Review. 22 (2003). 
Figure 1

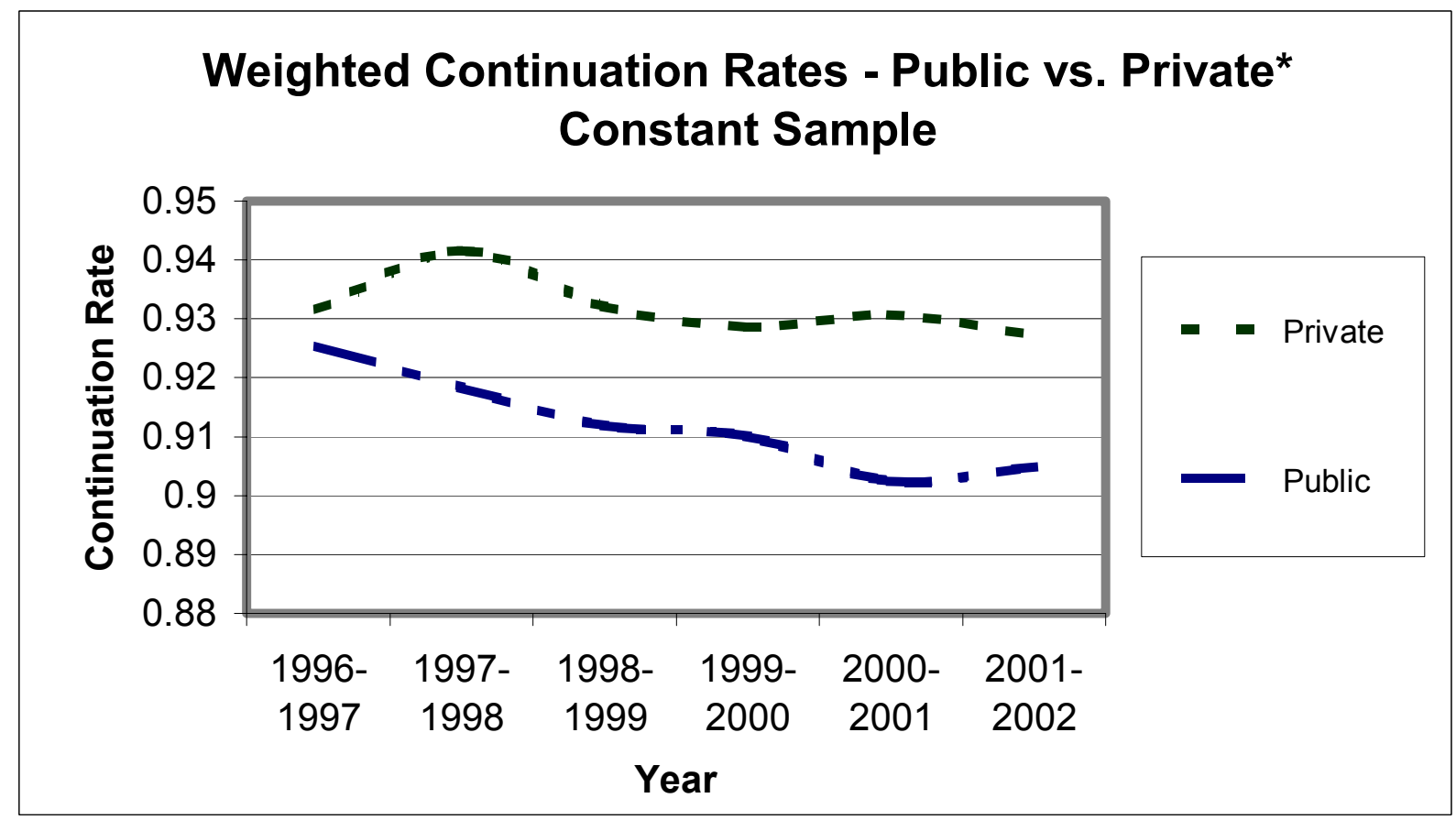

* Continuation rates calculated using weighted averages (by the number of faculty at an institution in year $t$ ) in the sample. 
Table 1

Weighted Continuation Rates, Four-Year Institutions*

Constant Sample

\begin{tabular}{|c|c|c|c|c|c|c|}
\hline & \multicolumn{2}{|c|}{ PhD } & \multicolumn{2}{|c|}{ Ma } & \multicolumn{2}{|c|}{$\mathbf{B a}$} \\
\hline & Public & Private & Public & Private & Public & Private \\
\hline 1996-1997 & 0.928 & 0.936 & 0.920 & 0.922 & 0.925 & 0.930 \\
\hline $1997-1998$ & 0.916 & 0.943 & 0.925 & 0.939 & 0.911 & 0.939 \\
\hline 1998-1999 & 0.910 & 0.936 & 0.919 & 0.930 & 0.877 & 0.920 \\
\hline 1999-2000 & 0.907 & 0.930 & 0.916 & 0.928 & 0.888 & 0.925 \\
\hline 2000-2001 & 0.902 & 0.933 & 0.902 & 0.927 & 0.918 & 0.929 \\
\hline 2001-2002 & 0.904 & 0.926 & 0.904 & 0.929 & 0.907 & 0.928 \\
\hline$n$ & \multicolumn{2}{|c|}{360} & \multicolumn{2}{|c|}{420} & \multicolumn{2}{|c|}{240} \\
\hline & & & \multicolumn{4}{|c|}{$\begin{array}{l}\text { * Continuation rates calculated using weighted } \\
\text { averages (by the number of faculty at an institution } \\
\text { in year } t \text { ) in the sample. }\end{array}$} \\
\hline
\end{tabular}


Table 2

Variable Means, All Years*

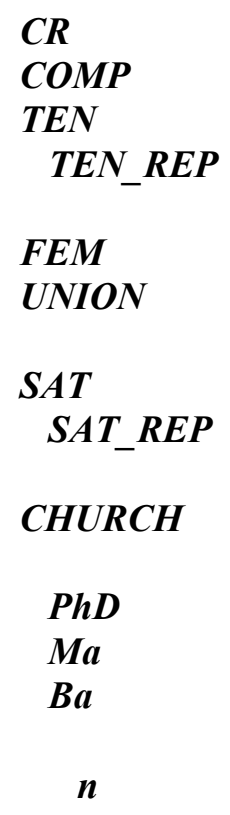

\begin{tabular}{c|c|}
\multicolumn{2}{c|}{ Variable Sample } \\
\hline Public & Private \\
\hline \hline 0.915 & 0.931 \\
68.2 & 71.4 \\
87.1 & 75.5 \\
0.022 & 0.079 \\
& \\
33.1 & 35.7 \\
0.231 & 0 \\
& \\
942.8 & 1126.4 \\
0.122 & 0.044 \\
& \\
0 & 0.448 \\
& \\
0.638 & 0.364 \\
0.272 & 0.307 \\
0.043 & 0.327 \\
\hline & \\
1635 & 1775
\end{tabular}

\begin{tabular}{c|c}
\multicolumn{2}{c}{ Constant Sample } \\
\hline Public & Private \\
\hline \hline 0.912 & 0.932 \\
69.3 & 74.3 \\
88.8 & 76.5 \\
0.011 & 0.077 \\
& \\
32.8 & 33.9 \\
0.192 & 0 \\
& \\
958.4 & 1184.6 \\
0.107 & 0.011 \\
& \\
0 & 0.505 \\
& \\
0.660 & 0.582 \\
0.282 & 0.268 \\
0.033 & 0.150 \\
\hline & \\
684 & 372
\end{tabular}

* Calculated using weighted averages (by the number of faculty at an institution in year $t$ ) in the sample. 


\section{Table 3}

Determinants of Associate Faculty Continuation Rates Weighted Regression Equations (absolute value t statistics)

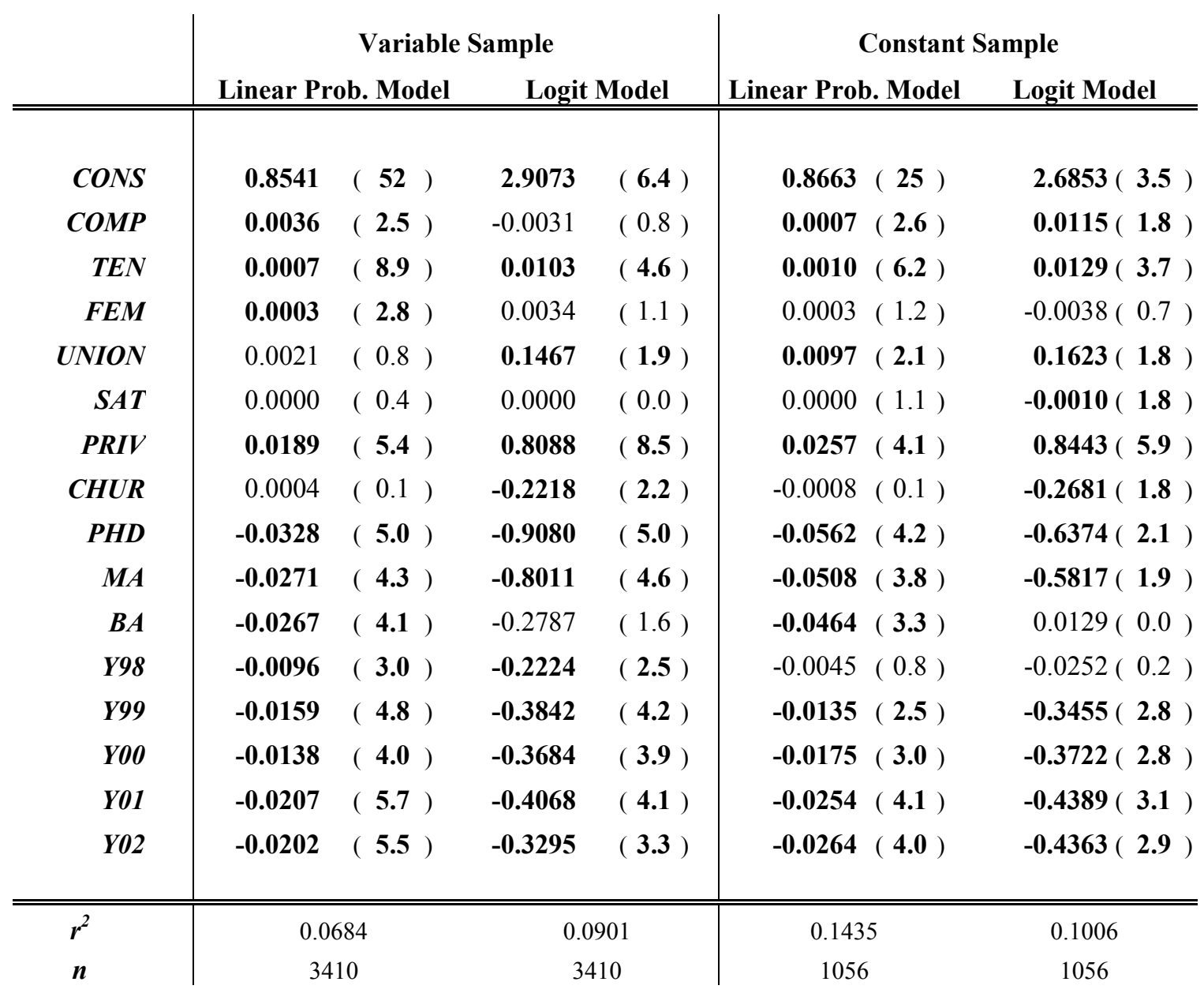

Equation weighted by the square root of the number of faculty in year $t$. Coefficients that are statistically significant at the $90 \%$ confidence interval in bold. Also included in equations are dichotomous variables for the reporting of tenure status and SAT score to control for non-reporting institutions, where $1=$ not reported, $0=$ reported.

\section{Variables}

CONS Intercept

COMP average compensation of the associate professors in institution, reported in tens of thousands of $\$$ in year $t$

TEN percent associate faculty tenured in institution in tear $t$

$\boldsymbol{F E M}$ proportion associate faculty female in institution in tear $t$

UNION 1 = faculty unionized at institution, $0=$ no union

$\boldsymbol{S A T}$ Mean SAT of entering freshman at institution, measured in tens

PRIV $1=$ private institution, $0=$ other

CHUR $1=$ church affiliated institution, $0=$ other

PHD $1=\mathrm{PhD}$ (highest degree) granting institution, $0=$ other

$\boldsymbol{M A} 1=\mathrm{Ma}$ (highest degree) granting institution, $0=$ other

two-year institutions are omitted

$\boldsymbol{B} \boldsymbol{A} 1=\mathrm{Ba}$ (highest degree) granting institution, $0=$ other

Y98 1 = observation from academic year 1997-1998, $0=$ other

Y99 1 = observation from academic year 1998-1999, $0=$ other

Y00 $1=$ observation from academic year 1999-2000, $0=$ other

Y01 1 = observation from academic year 2000-2001, $0=$ other

Y02 1 = observation from academic year 2001-2002, $0=$ other variable

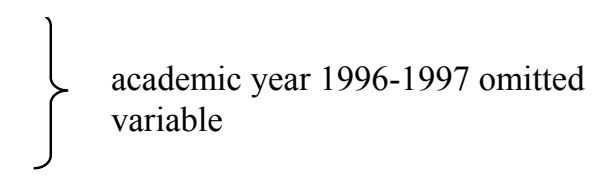


Appendix Table 1

Variable Sample and Constant Sample Size

By Institutional Characteristics

\begin{tabular}{|c|c|c|c|}
\hline & AAUP & $\begin{array}{l}\text { Variable } \\
\text { Sample } \\
\end{array}$ & $\begin{array}{c}\text { Constant } \\
\text { Sample } \\
\end{array}$ \\
\hline All & 8479 & 3410 & 1056 \\
\hline$P h D$ & 1210 & 713 & 360 \\
\hline$M a$ & 2486 & 1107 & 420 \\
\hline$B a$ & 3323 & 1320 & 240 \\
\hline TwoYear & 1460 & 270 & 36 \\
\hline Public & 4021 & 1635 & 684 \\
\hline$P h D$ & 839 & 512 & 252 \\
\hline$M a$ & 1304 & 615 & 294 \\
\hline$B a$ & 577 & 254 & 102 \\
\hline TwoYear & 1301 & 254 & 36 \\
\hline Private & 4458 & 1775 & 372 \\
\hline$P h D$ & 371 & 201 & 108 \\
\hline$M a$ & 1182 & 492 & 126 \\
\hline$B a$ & 2746 & 1066 & 138 \\
\hline TwoYear & 159 & 16 & . \\
\hline
\end{tabular}

